УДК 617.735:616-001.28:616-001.14/.15

Для цитирования: Потапов А.В., Герасимов А.В., Варакута Е.Ю., Солонский А.В., Свердева Ю.О., Аникина Е.Ю., Мустафина Л.Р., Шушпанова Т.В., Логвинов С.В. Реакция нейронов зрительного анализатора на комбинированное воздействие рентгеновских лучей и яркого света. Сибирский вестник психиатрии и наркологии. 2017; 4 (97): 10-14. https://doi.org/10.26617/1810-3111-2017-4(97)-10-14

\title{
Реакция нейронов зрительного анализатора на комбинированное воздействие рентгеновских лучей и яркого света
}

\section{Потапов А.В. ${ }^{1}$, Герасимов А.В. ${ }^{1,}$ Варакута Е.Ю. ${ }^{1}$, Солонский А.В. ${ }^{1}$, Свердева Ю.О. ${ }^{1}$,} Аникина Е.Ю. ${ }^{1}$, Мустафина Л.Р. ${ }^{1}$, Шушпанова Т.В. ${ }^{2}$, Логвинов С.В. ${ }^{1}$

${ }^{1}$ Сибирский государственный медицинский университет Россия, 634050, Томск, Московский тракт, 2

${ }^{2}$ Научно-исследовательский институт психического здоровья

Томский национальный исследовательский медииинский ичентр Российской академии наук

Россия, 634014, Томск, ул. Алеутская, 4

\section{PEЗЮME}

Цель - установить характер модифицирующего влияния яркого света на повреждения нейронов внутреннего ядерного и ганглионарного слоев сетчатки, вызываемые ионизирующей радиацией. В работе изучены структурные изменения нейронов внутреннего ядерного и ганглионарного слоев сетчатки у белых беспородных крыс-самцов $(\mathrm{n}=60)$ при комбинированном воздействии ионизирующей радиации в дозах 5, 10, 15 Гр и света (3500 лк, 48 ч). Результаты. Исследование показало, что реакции нейронов внутреннего ядерного и ганглионарного слоев после рентгеновского и комбинированного воздействий носят дозовую зависимость, в основном проявляются вакуолизацией и деструкцией органелл и наиболее выражены после комбинированного воздействия ионизирующей радиации в дозе 15 Гр и света (3500 лк, 48 ч). Анализ изменений содержания гиперхромных нейронов внутреннего ядерного и ганглионарного слоев показал, что после окончания воздействия ионизирующей радиации в дозах 10, 15 Гр количество гиперхромных клеток значительно превышает контрольные значения $(\mathrm{p}<0,05)$. После окончания комбинированного облучения ионизирующей радиации в дозах 10,15 Гр и высокоинтенсивного света происходит снижение данного показателя, что свидетельствует о срыве компенсаторноприспособительных механизмов с увеличением дозы облучения и усилением процессов деструкции.

\section{Ключевые слова: ассоциативные, мультиполярные нейроны, свет, рентгеновское излучение.}

\section{ВВЕДЕНИЕ}

В век научно-технического прогресса человек подвергается воздействию естественных и искусственных источников световой энергии с самой различной спектральной характеристикой и чрезвычайно обширным диапазоном интенсивности $[1,2$, 3]. Метод фототерапии в настоящее время используется при нарушениях циркадного ритма эндогенной или экзогенной природы, депрессиях, болезни Альцгеймера, при нарушении сна у пожилых людей $[4,5,6,7,8]$.

Эффекты воздействия ионизирующей радиации на человека формируются за счет природных, медицинских и техногенных источников ионизирующего излучения $[9,10]$. Поражение органа зрения ярким светом и ионизирующей радиацией возможно в случае крупных аварий на предприятиях атомной энергетики. Примером являются аварии на АЭС ТриМайл-Айленд (США), Чернобыльской АЭС (СССР) и АЭС «Фукусима» (Япония), когда радиоактивному загрязнению подверглись обширные территории разных стран $[11,12,13,14,15]$.

Цель исследования - установить характер модифицирующего влияния яркого света на повреждения нейронов внутреннего ядерного и ганглионарного слоев сетчатки, вызываемые ионизирующей радиацией.

\section{МАТЕРИАЛЫ И МЕТОДЫ}

Эксперименты проведены на 60 беспородных половозрелых белых крысах обоего пола массой 180-200 грамов. В первой, второй и третьей сериях опытов $(\mathrm{n}=15)$ животных подвергали тотальному воздействию рентгеновского излучения в дозах 5 , 10, 15 грей $(\Gamma \mathrm{p})$ с помощью аппарата РУМ-17 (мощность дозы 0,5 Гр/мин, напряжение 200 кВ, сила тока 15 мА, фильтр 0,5 мм $\mathrm{Cu}$, фокусное расстояние $60 \mathrm{cm).} \mathrm{Животных} \mathrm{четвертой,} \mathrm{пятой} \mathrm{и} \mathrm{шестой} \mathrm{групп}$ $(\mathrm{n}=15)$ подвергали комбинированному воздействию ионизирующей радиации $(5,10,15$ Гр) и равномерному световому облучению люминесцентными лампами ЛБ-40 (3500 лк, 48 ч) с интервалом в 1 час.

Для облучения светом использовали специальную установку из прямоугольных рефлекторов с вмонтированными в них лампами. Количество животных на каждую экспериментальную точку составляет 5 .

В качестве контроля $(\mathrm{n}=30)$ использовали интактных крыс, содержавшихся в условиях искусственного светового режима (12 ч день, 12 ч ночь) с интенсивностью дневного освещения 25 лк. Опыты были проведены с соблюдением принципов гуманности, изложенных в Директивах Европейского Сообщества (86/609/ЕС), и одобрены Этическим комитетом Сибирского государственного медицинского университета. 
Взятие материала осуществляли после умерщвления животных декапитацией сразу после окончания экспериментальных воздействий. Центральные участки задней стенки глаза фиксировали в 2,5\% глютаральдегиде на какодилатном буфере $(\mathrm{PH} 7,4)$, постфиксировали в $1 \%$ растворе четырехокиси осмия и заливали в эпон. Ультратонкие срезы контрастировали уранилацетатом и цитратом свинца, просматривали в электронном микроскопе JEM-100 CXII. На полутонких срезах, окрашенных толуидиновым синим, вычисляли процент гиперхромных и пикноморфных нейронов внутреннего ядерного и ганглионарного слоев на 200 клеток. Подсчет производили в окулярной рамке на площади 900 мкм ${ }^{2}$ при увеличении $10 \times 90$. Для оценки достоверности различий при сравнении средних величин использовали критерий Манна-Уитни.

\section{РЕЗУЛЬТАТЫ И ОБСУЖДЕНИЕ}

После окончания воздействия ионизирующей радиации в дозах 5 и 10 Гр в амакринных и горизонтальных нейронах наблюдается отек митохондрий и цистерн эндоплазматического ретикулума. Перикарионы значительной доли ассоциативных нейроцитов внутреннего ядерного слоя после окончания воздействия ионизирующей радиации в дозе 10 Гр характеризуются уменьшением объема, вакуолизацией, деструктивными нарушениями подавляющего большинства органелл. Ядра в подобных клетках содержат диффузно распыленные хроматиновые гранулы и характеризуются наличием одного, изредка двух ядрышек умеренной величины. После окончания воздействия ионизирующей радиации в дозе 15 Г'р изменения большей части ассоциативных нейронов внутреннего ядерного слоя проявляются центральным и периферическим хроматолизом и уменьшением объема ядра. Измененные подобным образом нейроны имеют округлую форму. Горизонтальные, биполярные и амакринные нейроны весьма часто вакуолизированы, содержат в перикарионах и отростках мембранные комплексы.

В биполярных и амакринных нейронах внутреннего ядерного слоя после окончания комбинированного воздействия ионизирующей радиации в дозах 5 и 10 Гр и высокоинтенсивного света наблюдаются отек и деструкция органелл, появление крупных вакуолей и мультивезикулярных телец. Встречаются ассоциативные нейроны, перикарионы которых содержат мембранные комплексы, а электронная плотность цито- и кариоплазмы повышена. После окончания комбинированного воздействия ионизирующей радиации в дозе 15 Гр и высокоинтенсивного света в ассоциативных нейронах внутреннего ядерного слоя преобладают хроматолитические изменения разной выраженности, деструкция органелл, вакуолизация ядрышка или его отсутствие, что, по-видимому, отражает снижение метаболизма и функции, вплоть до истощения и последующей гибели клетки.
Структурные реакции мультиполярных нейронов ганглионарного слоя после рентгеновского облучения в дозах $5,10,15$ Гр в основном характеризуются изменением содержания субстанции Ниссля в перикарионах нервных клеток. Гранулярная эндоплазматическая сеть данных нейронов часто утрачивает часть своих рибосом и фрагментируется, а из её цистерн образуются вакуоли различных размеров. В части нейроцитов, напротив, наблюдается активация репаративных процессов, к которым относится увеличение объема ядрышка, числа рибосом и элементов гранулярной сети в перинуклеарной области.

При комбинированных воздействиях в клетках наблюдается дальнейшее разрушение рибосом и мембран, приводящее к более выраженному нарушению белоксинтезирующей функции. В цитоплазме подавляющего числа клеток содержатся крупные вакуоли, мембранные комплексы и миелиноподобные тельца. Некоторые ганглионарные нейроны характеризуются деформацией ядер, уменьшением размеров ядрышек и снижением содержания в них гранулярного компонента. В таких случаях изменения сопровождались отеком клетки и другими деструктивными явлениями (рис. 1).

Анализ содержания гиперхромных нейронов ганглионарного слоя показывает, что их число в серии с рентгеновским облучением в дозе 5 Гр достоверно не отличается от значений контроля. После окончания комбинированного облучения ионизирующей радиации в дозе 5 Гр и света количество гиперхромных нейронов ганглионарного слоя превышает контрольные значения в 10 раз $(\mathrm{p}<0,05)$ (рис. 2).

После окончания комбинированного воздействия (10 Гр, 3500 лк) содержание гиперхромных нейронов ганглионарного слоя оказалось в 1,7 раза больше, а при комбинации ионизирующей радиации и высокоинтенсивного света (15 Гр, 3500 лк) в 2 раза меньше, чем в сериях с одним рентгеновским воздействием. Увеличение содержания гиперхромных клеток после окончания воздействия ионизирующей радиации в дозах 10, 15 Гр и комбинированного облучения (10 Гр, 3500 лк), по-видимому, свидетельствует об активации репарационных процессов в данных сериях. Содержание пикноморфных ганглионарных нейронов в данных сериях эксперимента достоверно не отличается от такового в контроле.

Таким образом, изменения нейронов внутреннего ядерного и ганглионарного слоев, обнаруженные при воздействии высоких доз ионизирующей радиации, и их комбинации со светом носят дозовую зависимость и в основном проявляются хроматолизом различной степени выраженности и увеличением содержания гиперхромных клеток, более характерным для комбинированного воздействия. 


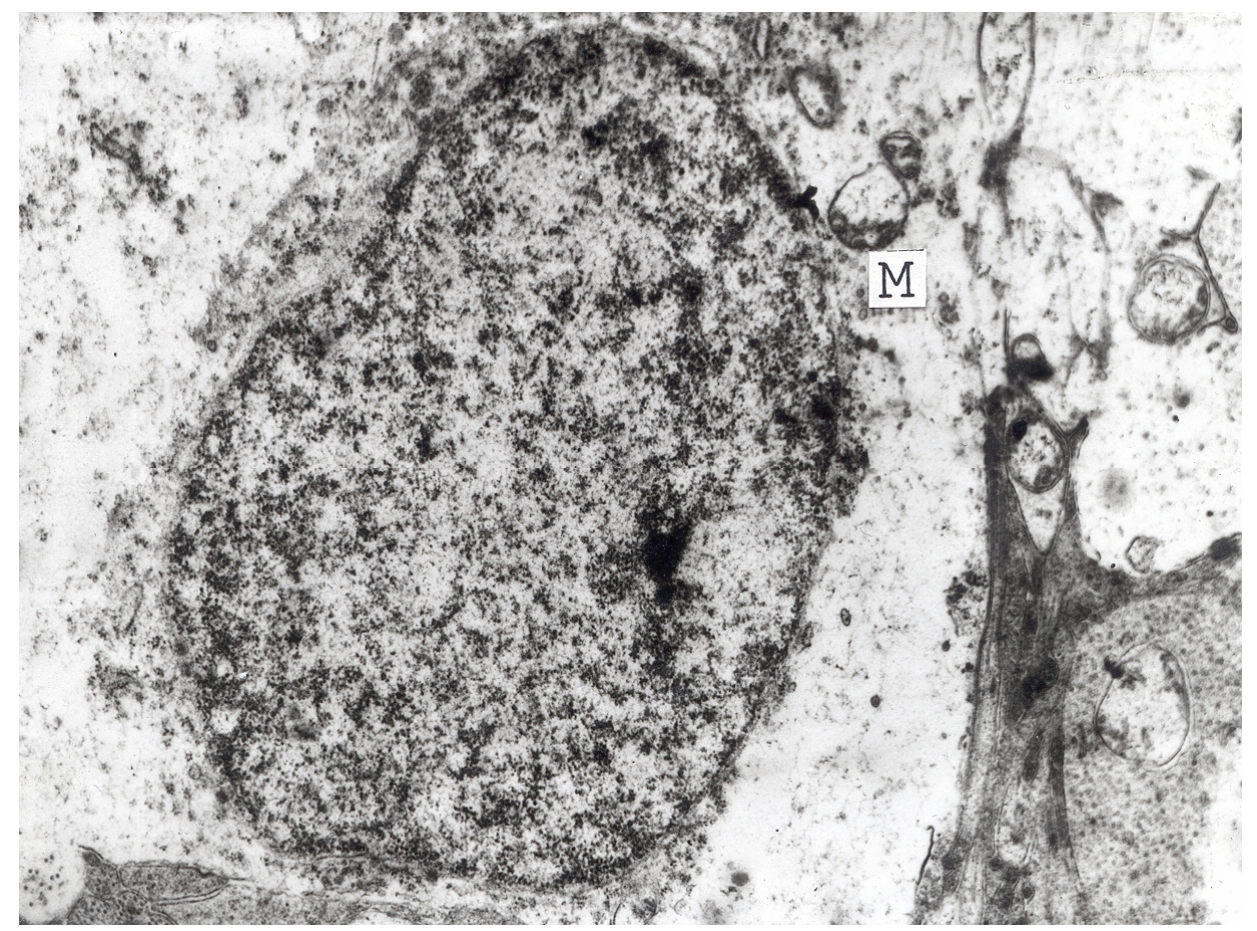

\section{Р и с у н о к 1 . Тотальный хроматолиз и отек митохондрий в мультиполярном нейроне} ганглионарного слоя после комбинированного облучения (5 Гр +3500 лк, 2 суток)

П р и м е ч а н и е. М - митохондрии. Увеличение 7200.

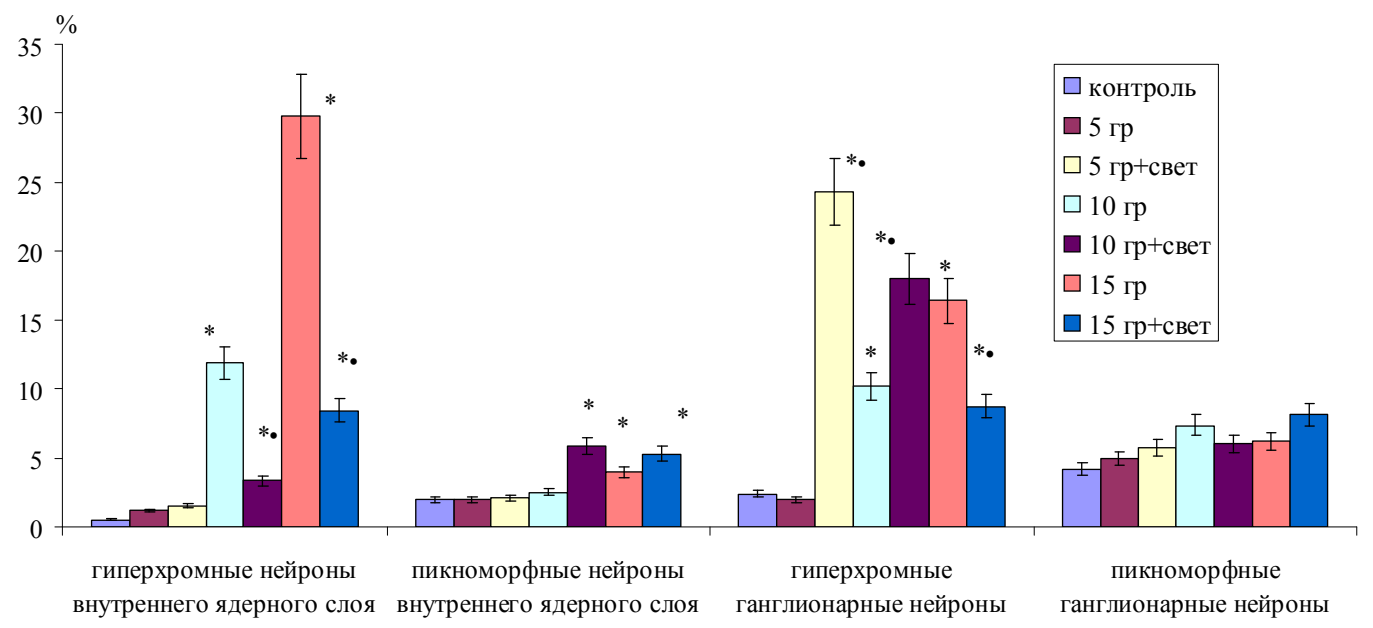

Р и с у н о к 2. Содержание гиперхромных и пикноморфных нейронов внутреннего ядерного и ганглионарных слоев после окончания рентгеновского и комбинированного воздействий

П р и м е ч а н и е. Статистически достоверные отличия $p<0,05$ при сравнении: * - различных облучений с контролем; •- комбинированного и рентгеновского воздействий.

\section{ЗАКЛЮЧЕНИЕ}

Изменения нейронов внутреннего ядерного и ганглионарного слоев при воздействии высоких доз ионизирующей радиации $(5,10,15$ Гр) и их комбинации со светом (3500 лк, 48 ч) проявляются хроматолитическими изменениями, вакуолизацией и деструкцией органелл.

Необходимо отметить, что после окончания комбинированного воздействия ионизирующей радиации и света в ассоциативных нейронах внутреннего ядерного слоя увеличивается число свободных рибосом и ядрышек, что указывает на усиление репа- рации в этот срок эксперимента. Активация репарационных процессов является закономерной структурно-адаптационной реакцией, приводящей к ускоренному обновлению структур, которые, приобретая новые качественные свойства, становятся более адаптированными к действующему фактору. Возможно, изучаемые воздействия усиливают функциональную активность части ассоциативных и ганглионарных нейронов внутренних слоев сетчатки и приводят к активной мобилизации имеющихся в ней ультраструктур, следствием чего является увеличение числа гиперхромных клеток. Резкое 
снижение данного показателя при комбинированных облучениях говорит о срыве компенсаторноприспособительных механизмов с увеличением дозы облучения и усилением процессов деструкции. Появление пикноморфных ассоциативных нейронов внутреннего ядерного слоя после комбинированного облучения ионизирующей радиации в дозе 15 Гр и света соответствует деструктивным изменениям в нейросенсорных клетках и активации данных процессов во внутренних слоях сетчатки.

\section{КОНФЛИКТ ИНТЕРЕСОВ}

Авторы заявляют об отсутствии конфликта интересов в связи с публикацией данной статьи.

\section{ИСТОЧНИК ФИНАНСИРОВАНИЯ}

Авторы заявляют об отсутствии финансирования при проведении исследования.

\section{СООТВЕТСТВИЕ ПРИНЦИПАМ ЭТИКИ}

Исследование проведено с соблюдением норм современной биомедицинской этики и этических стандартов, разработанным в соответствии с Хельсинской декларацией ВМА (протокол заседания этического комитета ФГБОУ ВО «Сибирский государственный медицинский университет» Минздрава РФ № 3 от 06.04.2007).

\section{ЛИТЕРАТУРА}

1. Contín M.A., Benedetto M.M., Quinteros-Quintana M.L, Guido M.E. Light pollution: the possible consequences of excessive illumination on retina. Eye (Lond). 2016; 30 (2): 255-263.

2. Mangan M.S., Arıcı C., Atalay E., et al. Four Cases of Pediatric Photokeratitis Present to the Emergency Department After Watching the Same Theater Show. Turk. J. Ophthalmol. 2015; 45 (5): 226-228.

3. Sayman Muslubaş I., Hocaoğlu M., Arf S., et al. Macular Burns from Nonmedical Lasers. Turk. J. Ophthalmol. 2016: 46 (3): 138143.

4. Симуткин Г.Г. Особые паттерны течения аффективных расстройств. Томск: Изд-во Том. ун-та, 2010: 416.

5. Симуткин Г.Г., Счастный Е.Д., Якутенок Л.П., Кудякова Т.А., Потапкина Е.В., Рогозина Т.А. Изучение клинической эффек- тивности комбинированного применения флуоксетина и светотерапии при депрессивных расстройствах. Тезисы докладов XII Российского национального конгресса «Человек и лекарство». М., 2005: 546.

6. Rutten S., Vriend C., Smit J.H., et al. A double-blind randomized controlled trial to assess the effect of bright light therapy on depression in patients with Parkinson's disease. BMC Psychiatry. 2016; 6: 355-364.

7. Montagnon F. Phototherapie et psychiatrie. Rev. fr. psychiat. et psychol. med. 2001; 5 (51): 23-25.

8. Szabo Z. Light therapy increases visual contrast sensitivity in seasonal affective disorder. Psychiatry Research. 2004; 126 (1): $15-21$

9. Gale R.P. Medical and policy considerations for nuclear and radiation accidents, incidents and terrorism. Curr Opin Hematol. 2017; 24 (6): 496-501.

10. Melo D.R., Miller D.L., Chang L., et al. Organ Doses From Diagnostic Medical Radiography-Trends Over Eight Decades (1930 to 2010). Health Phys. 2016; 111 (3): 235-255.

11. Babenko T.F., Fedirko P.A., Dorichevska R.Y., et al. The risk of macular degeneration development in persons antenatally irradiated as a result of Chornobyl NPP accident. Probl. Radiac. Med Radiobiol. 2016; 21: 172-177.

12. Mikhailovskaya L.N., Molchanova I.V., Pozolotina V.N., Zhuravlev YN. et al. Radioactive contamination of the soil-plant cover $t$ certain locations of Primorsky Krai, SakhalinIsland and Kamchatka Peninsula: Assessment of the Fukushima fallout. $J$. Environ. Radioact. 2017; 172: 1-9.

13. Sugita M.M., Miyakawa M. Perspective on the nuclear power plant accident caused by the great east Japan earthquake and tsunami: health impairment risks due to pollution by radioactive materials from the damaged plant as recognized by experts and by the general population and role of the experts. Nihon Eiseigaku Zasshi. 2012; 67 (4): 514-523.

14. Hasegawa A., Tanigawa K., Ohtsuru A., et al. Health effects of radiation and other health problems in the aftermath of nuclear accidents, with an emphasis on Fukushima. Lancet. 2015; 386 (9992): 479-488.

15. Han Y.Y., Youk A.O., Sasser H., Talbott E.O. Cancer incidence among residents of the Three Mile Island accident area: 19821995. Environ Res. 2011; 111 (8): 1230-1235.

Поступила в редакцию 6.10.2017 Утверждена к печати 30.10.2017

Потапов Александр Валерьевич, д.м.н., проф. кафедры гистологии, эмбриологии и цитологии.

Герасимов Александр Владимирович, д.м.н., проф. кафедры гистологии, эмбриологии и цитологии.

Солонский Анатолий Владимирович, д.м.н., в.н.с. лаборатории психонейроиммунологии и нейробиологии.

Мустафина Лилия Рамильевна, д.м.н., проф. кафедры гистологии, эмбриологии и цитологии.

Шушпанова Тамара Владимировна, К.м.Н., в.н.с. лаборатории психонейроиммунологии и нейробиологии.

Свердева Юлия Олеговна, аспирант каф. гистологии, эмбриологии и цитологии.

Варакута Елена Юрьевна, д.м.н, зав. каф. нормальной анатомии человека с курсом топографической анатомии и оперативной хирургии. Аникина Елена Юрьевна, к.м.н., ассистент каф. нормальной анатомии человека с курсом топографической анатомии и оперативной хирургии.

Логвинов Сергей Валентинович, д.м.н., зав. каф. гистологии, эмбриологии и цитологии.

Потапов Александр Валерьевич, potalex@mail.ru

УДК 617.735:616-001.28:616-001.14/.15

For citation: Potapov A.V., Gerasimov A.V., Varakuta E.Yu., Solonsky A.V., Sverdeva Y.O., Anikina E.Yu., Mustafina L.R., Shushpanova T.V., Logvinov S.V. Reaction of neurons of inner layers of the retina on combined influence of ionizing radiation and bright light. Siberian Herald of Psychiatry and Addiction Psychiatry. 2017; 4 (97): 10-14. https://doi.org/10.26617/1810-3111-20174(97)-10-14

\section{Reaction of neurons of inner layers of the retina on combined influence of ionizing radiation and bright light}

Potapov A.V. ${ }^{1}$, Gerasimov A.V. ${ }^{1}$, Varakuta E.Yu. ${ }^{1}$, Solonsky A.V. ${ }^{2}$, Sverdeva Y.O. ${ }^{1}$, Anikina E.Yu. ${ }^{1}$, Mustafina L.R. ${ }^{1}$, Shushpanova T.V. ${ }^{2}$, Logvinov S.V. ${ }^{1}$ 


\author{
${ }^{1}$ Siberian State Medical University \\ Moskovsky Trakt 2, 634050, Tomsk, Russian Federation \\ ${ }^{2}$ Mental Health Research Institute, Tomsk National Research Medical Center, Russian Academy of Sciences \\ Aleutskaya Street 4, 634014, Tomsk, Russian Federation
}

\title{
ABSTRACT
}

Objectives. Structural changes of the inner nuclear and ganglion cell layers of the retina in white mongrel male rats $(n=60)$ were studied with the combined effects of ionizing radiation at a dose of 5, 10, $15 \mathrm{Gr}$ and light ( $3500 \mathrm{Lux}, 48 \mathrm{~h})$. Results. The study showed that the reactions of neurons of the inner nuclear and ganglionic layers after the X-ray and combined layers depended on the dose, such changes as vacuolization and destruction of organelles occurred and are most pronounced when combined with ionizing radiation at a dose of $15 \mathrm{Gr}$ and light. An analysis of the number of hyperchromic neurons of the internal nuclear and ganglionic layers showed that after the end of exposure to ionizing radiation at doses of $10,15 \mathrm{Gr}$, the amount of hyperchromic cells was much larger than the control values ( $p$ $<0.05$ ). After the end of the combined irradiation of ionizing radiation at a dose of $10,15 \mathrm{Gr}$ and high-intensity light, this index decreased, that indicated the failure of compensatory and adaptive mechanisms with an increase in the radiation dose and the intensification of the destruction processes.

\section{Keywords: protein oxidative modification, lipid peroxidation, blood plasma, antialcohol therapy, alcoholism.}

\section{REFERENCES}

1. Contín M.A., Benedetto M.M., Quinteros-Quintana M.L, Guido M.E. Light pollution: the possible consequences of excessive illumination on retina. Eye (Lond). 2016; 30 (2): 255-263.

2. Mangan M.S., Arıcı C., Atalay E., et al. Four Cases of Pediatric Photokeratitis Present to the Emergency Department After Watching the Same Theater Show. Turk. J. Ophthalmol. 2015; 45 (5): 226-228.

3. Sayman Muslubas I., Hocaoğlu M., Arf S., et al. Macular Burns from Nonmedical Lasers. Turk. J. Ophthalmol. 2016: 46 (3): 138-143.

4. Simutkin G.G. Osobye patterny techeniya affektivnykh rasstroistv [Special patterns of the course of affective disorders]. Tomsk: Izd-vo Tom. un-ta, 2010, 416 s. (in Russian).

5. Simutkin G.G., Schastnyi E.D., Yakutenok L.P., Kudyakova T.A., Potapkina E.V., Rogozina T.A. Izuchenie klinicheskoi effektivnosti kombinirovannogo primeneniya fluoksetina i svetoterapii pri depressivnykh rasstroistvakh [Study of the clinical efficacy of combined use of fluoxetine and light therapy in depressive disorders]. Tezisy dokladov XII Rossiiskogo natsional'nogo kongressa «Chelovek i lekarstvo». Moscow, 2005: 546. (in Russian).

6. Rutten S., Vriend C., Smit J.H., et al. A double-blind randomized controlled trial to assess the effect of bright light therapy on depression in patients with Parkinson's disease. BMC Psychiatry. 2016; 6: 355-364.

7. Montagnon F. Phototherapie et psychiatrie. Rev. fr. psychiat. et psychol. med. 2001; 5 (51): 23-25.

8. Szabo Z. Light therapy increases visual contrast sensitivity in seasonal affective disorder. Psychiatry Research. 2004; 126 (1): 15-21.

9. Gale R.P. Medical and policy considerations for nuclear and radiation accidents, incidents and terrorism. Curr Opin Hematol. 2017; 24 (6): 496-501.
10. Melo D.R., Miller D.L., Chang L., et al. Organ Doses From Diagnostic Medical Radiography-Trends Over Eight Decades (1930 to 2010). Health Phys. 2016; 111 (3): 235-255.

11. Babenko T.F., Fedirko P.A., Dorichevska R.Y., et al. The risk of macular degeneration development in persons antenatally irradiated as a result of Chornobyl NPP accident. Probl. Radiac. Med Radiobiol. 2016; 21: 172-177.

12. Mikhailovskaya L.N., Molchanova I.V., Pozolotina V.N., Zhuravlev YN. et al. Radioactive contamination of the soil-plant cover $\mathrm{t}$ certain locations of Primorsky Krai, SakhalinIsland and Kamchatka Peninsula: Assessment of the Fukushima fallout. J. Environ. Radioact. 2017; 172: 1-9.

13. Sugita M.M., Miyakawa M. Perspective on the nuclear power plant accident caused by the great east Japan earthquake and tsunami: health impairment risks due to pollution by radioactive materials from the damaged plant as recognized by experts and by the general population and role of the experts. Nihon Eiseigaku Zasshi. 2012; 67 (4): 514-523.

14. Hasegawa A., Tanigawa K., Ohtsuru A., et al. Health effects of radiation and other health problems in the aftermath of nuclear accidents, with an emphasis on Fukushima. Lancet. 2015; 386 (9992): 479-488.

15. Han Y.Y., Youk A.O., Sasser H., Talbott E.O. Cancer incidence among residents of the Three Mile Island accident area: 19821995. Environ Res. 2011; 111 (8): 1230-1235.

Received October 6.2017 Accepted October 30.2017

Potapov Alexander V., MD, Professor of Histology, Embryology and Cytology Department, Siberian State Medical University, Tomsk, Russian Federation.

Gerasimov Alexander V., MD, Professor of Histology, Embryology and Cytology Department, Siberian State Medical University, Tomsk, Russian Federation.

Solonsky Anatoly V., MD, leading researcher of Psychoneuroimmunology and Neurobiology Laboratory, Mental Health Research Institute, Tomsk National Research Medical Center, Russian Academy of Sciences, Tomsk, Russian Federation.

Mustafina Lilia R., MD, Professor of Histology, Embryology and Cytology Department, Siberian State Medical University, Tomsk, Russian Federation.

Shushpanova Tamara V., PhD, leading researcher of Psychoneuroimmunology and Neurobiology Laboratory, Mental Health Research Institute, Tomsk National Research Medical Center, Russian Academy of Sciences, Tomsk, Russian Federation.

Sverdeva Julia O., postgraduate student of Histology, Embryology and Cytology Department, Siberian State Medical University, Tomsk, Russian Federation.

Varakuta Elena Yu., MD, Head of Human Normal Anatomy Department with course of Topographic Anatomy and Operative Surgery Siberian State Medical University, Tomsk, Russian Federation.

Anikina Elena Yu., PhD, assistant of Human Normal Anatomy Department with course of Topographic Anatomy and Operative Surgery Siberian State Medical University, Tomsk, Russian Federation.

Logvinov Sergey V., MD, Head of Histology, Embryology and Cytology Department, Siberian State Medical University, Tomsk, Russian Federation. 